\title{
Pediatric Pseudotumor Cerebri: Descriptive Epidemiology
}

\author{
Kevin Gordon
}

\begin{abstract}
Objective: To determine the epidemiological profile for pediatric pseudotumor cerebri. Methods: A retrospective case series was identified from a geographically limited region of 205,765 children aged 2-15 years at the only tertiary care pediatric hospital with all pediatric neurologists and ophthalmologists. Health records identified 35 children with ICD9 code 348.2 (benign intracranial hypertension) presenting between April 1, 1979 and March 31, 1994. After chart review, 29 cases were identified which satisfied modified Dandy's diagnostic criteria for pseudotumor cerebri. Results: The 29 cases ranged in age from 3-15 years. The annual incidence of symptomatic disease was 0.9 per 100,000 children $(95 \% \mathrm{CI} 0.6,1.4)$. Cases were 2.7 times more likely to be female $\left(21 / 29, \mathrm{X}^{2} \mathrm{p}=.01\right)$ and twice as likely to be adolescent (age 12-15 years), $\left(\mathrm{X}^{2} \mathrm{p}=.04\right)$. Based upon these distinctions, the following estimates of age and sex specific disease incidence were derived (based upon 100,000 child years of exposure): male age 2-11 years: 0.4 ; male age $12-15$ years: 0.8 ; female age $2-11$ years: 1.1 ; female age 12-16 years: 2.2. Conclusions: These data appear to be unique for its the estimation of age and sex specific incidence rates for pediatric pseudotumor cerebri.
\end{abstract}

\begin{abstract}
RÉSUMÉ: Épidémiologie descriptive du syndrome d'hypertension intracrânienne bénigne. Objectif: Déterminer le profil épidémiologique du syndrome d'hypertension intracrânienne bénigne. Méthodes: Nous avons identifié rétrospectivement une série de cas provenant d'une région géographique circonscrite comprenant 205,765 enfants âgés de 2 à 15 ans, desservie par un seul hôpital de soins pédiatriques tertiaires. Notre série inclut les cas de tous les neurologues et ophtalmologistes pédiatriques. Une revue des dossiers a identifié 35 enfants avec le code CIM-9 348.2 (hypertension intracrânienne bénigne) qui ont été évalués entre le 1 avril 1979 et le 31 mars 1994. Suite à l'évaluation de ces dossiers, 29 cas satisfaisaient aux critères diagnostiques modifiés de Dandy pour l'hypertension intracrânienne bénigne. Résultats: Les 29 cas étaient âgés de 3 à 15 ans. L'incidence annuelle de la maladie symptomatique était de 0.9 par 100,000 enfants $(95 \%$ IC $0.6,1.4)$. Les cas avaient 2.7 fois plus de chance d'être des filles $\left(21 / 29, X^{2} p=.01\right)$ et deux fois plus de chance d'être des adolescents (âge 12 à 15 ans), ( $X^{2} p=$ .04). Suite à ces observations, des estimés de l'incidence de la maladie par âge et par sexe ont été calculés (basés sur une exposition de 100,000 années enfants): 0.4 pour les garçons de 2 à 11 ans; 0.8 pour les garçons de 12 à 15 ans; 1.1 pour les filles de 2 à $11 ; 2.2$ pour les filles de 12 à 16 ans. Conclusion: Ces données semblent uniques pour l'estimation de l'incidence par âge et par sexe du syndrome d'hypertension intracrânienne bénigne.
\end{abstract}

Can. J. Neurol. Sci. 1997; 24: 219-221

Very little is known about the descriptive epidemiology of pediatric pseudotumor cerebri. As the only tertiary care pediatric hospital within a provincially based health care system, our population was ideally suited to describe the basic epidemiology of this condition.

The aim of this study was to estimate population based incidence rates and to provide demographic and anthropometric data on incident cases of pseudotumor cerebri diagnosed within our catchment area between 1979 and 1994.

\section{Methods}

The IWK Grace Health Centre is the only tertiary care pediatric hospital serving the provinces of Nova Scotia and Prince Edward Island within Canada. It is the only facility within these provinces with pediatric neurologists and pediatric ophthalmologists.
Between April 1, 1979, and March 31, 1994, health records identified children with a discharge diagnosis of benign intracranial hypertension (ICD9 code 348.2). Charts were reviewed, and cases were included only if they fulfilled the modified Dandy's diagnostic criteria for pseudotumor cerebri' (Table 1). Other inclusion criteria (Table 1) included ages 2-15, and residency within either Nova Scotia or Prince Edward Island at the time of the admission. The following information was abstracted from the charts for the purposes of this study: sex, date of birth, date of admission, weight, height, and symptom duration. As all

From the IWK Grace Health Centre, Department of Pediatrics, Dalhousie University, Halifax.

RECEIVED OCTOBER 11, 1996. ACCEPTED IN FINAL FORM JANUARY 31, 1997.

This paper was presented in part at the International Child Neurology Society meeting in San Francisco, October, 1994.

Reprint requests to: Kevin Gordon, IWK - Grace Health Centre, 5850 University Avenue, Box 3070, Halifax, Nova Scotia, Canada B3J 3G9 
Table 1: Inclusion Criteria.

Age 2-15 years

Residency within tertiary catchment area (Nova Scotia and Prince Edward Island)

Awake and alert

Symptoms and signs of increased intracranial pressure

No localizing neurological signs (excluding abducens nerve paresis)

Normal CT scan

Increased CSF pressure ( $>200 \mathrm{~mm} \mathrm{H}_{2} \mathrm{O}$ non obese, $>250 \mathrm{~mm} \mathrm{H}_{2} \mathrm{O}$ obese)

Normal CSF composition

No other cause of intracranial hypertension present

cases identified in this manner had been seen by one of the pediatric neurologists, an audit of a diagnostic database maintained by the pediatric neurologists was performed in order to confirm that all incident cases had been captured.

Disease incidence rates were calculated by the appropriate methodology using denominators derived from the 1986 Canadian census data. ${ }^{2} 95 \%$ confidence limits were estimated. ${ }^{3}$ Age and sex differences were examined using chi square analysis, with expected values from the population data. For significant age and sex differences, separate age and sex specific rates were calculated.

Data processing and analysis were performed using Epi Info v6.0. ${ }^{4}$ Weight and height data were standardized using the nutritional anthropometric module of Epi Info. ${ }^{4}$ Within this module, anthropometric calculations were derived from work from the National Center for Health Statistics and the Center for Disease Control. ${ }^{5}$

\section{RESULTS}

Health records identified 35 patients whose discharge diagnosis was benign intracranial hypertension (ICD9 code 348.2). When reviewed, 6 charts were excluded because of symptomatic intracranial hypertension (Sanfillipo syndrome, Fanconi's anemia with sepsis and subarachnoid hemorrhage, renal failure as terminal event, cerebral contusion with subarachnoid hemorrhage, brainstem tumor, myelocytic leukemia). Four patients with medication exposure (isotretinoin, tetracycline $(\mathrm{N}=2)$, and indomethacin) were included. The remaining twenty-nine patients fulfilled all entry criteria. 1986 Canadian census data identified the combined population aged 2-15 years of Nova Scotia and Prince Edward Island as 205,765. ${ }^{2}$

There were significantly more females $(\mathrm{N}=21)$ than males $(\mathrm{N}=8)(\mathrm{p}=.01)$. The mean age at admission was 10.9 years (range $31 / 2-15 \mathrm{yr})$. There were more adolescents $(12-15 \mathrm{yr})(\mathrm{N}=$ 14) than children $(2-11 \mathrm{yr})(\mathrm{N}=15)(\mathrm{p}=.04)$.

Patients had been symptomatic for between $1 / 2$ and 16 weeks (25\% tile: $1 \frac{1}{2} \mathrm{wk}, 50 \%$ tile: $2 \mathrm{wk}, 75 \%$ tile: $4.5 \mathrm{wk}$ ). When corrected for date of symptom onset, there did not appear to be any significant seasonal presentation, nor any temporal clustering of incident cases.

The mean $z$-score for weight was 1.6 (SD = 1.8), and height was $0.7(\mathrm{SD}=1.3)$. Both these values were significantly above normal ( $p<.001$ and $p=.006$, respectively). $45 \%$ of the children were beyond the 95 th percentile of weight by age $(95 \% \mathrm{CI}$ $27-64 \%$ ) while $18 \%$ of the children were beyond the 95 th percentile of height by age (95\% CI 6-37\%). There was no association of obesity with sex or age.
Table 2: Age and Sex Specific Average Annual Incidence of Pseudotumor cerebri (Rates are per 100,000 children)

\begin{tabular}{|c|c|c|c|c|c|c|c|}
\hline \multirow[b]{2}{*}{ Age group } & \multicolumn{2}{|c|}{ Males } & \multicolumn{2}{|c|}{ Females } & \multicolumn{3}{|c|}{ Total } \\
\hline & No. & Rate & No. & Rate & No. & Rate & $95 \% \mathrm{CI}$ \\
\hline $2-11$ yrs & 4 & 0.4 & 11 & 1.1 & 15 & 0.7 & $0.4,1.2$ \\
\hline $12-15 \mathrm{yrs}$ & 4 & 0.8 & 10 & 2.2 & 14 & 1.5 & $0.8,2.5$ \\
\hline All ages & 8 & 0.5 & 21 & 1.4 & 29 & 0.9 & $0.6,1.4$ \\
\hline $95 \% \mathrm{CI}$ & & $0.2,1.0$ & & $0.9,2.2$ & & & \\
\hline
\end{tabular}

Overall the annual incidence rate of pseudotumor cerebri was 0.9 per 100,000 children $(95 \%$ CI: $0.6,1.4)$. Separate age and sex specific incidence rates are shown in Table 2 . There were no more cases in the second half of the period reviewed, suggesting that for at least the past 15 years, the incidence rates appear to be stable.

\section{Discussion}

We have been able to provide a reasonably precise estimate of the incidence of pediatric pseudotumor cerebri: 0.9 cases per 100,000 children. The only similar data are those of Radhakrishnan et al. ${ }^{6}$ who published an age specific incidence rate in the 15-24 year old population of 2.6 cases per 100,000 population. Our data demonstrates an increasing incidence rate of pseudotumor cerebri in adolescents (12-15 years) when compared to children (2-11 years). If this trend, were to be projected into young adulthood, estimates of the incidence would likely agree closely with those of Radhakrishnan. Another North American study, by Durcan ${ }^{7}$ has published a crude annual incidence of 1.0 cases per 100,000 population aged 11-46 years, similar to that of Radhakrishnan; however age and sex specific incidence rates were not provided.

There has been discussion as to whether the noted female predilection of pseudotumor cerebri in adults ${ }^{7-9}$ applies to children. ${ }^{10}$ Most pediatric studies published to date have demonstrated an excess of males. ${ }^{11-14}$ Our population based study is not consistent with these previous studies, as it suggests a female predilection in both pre- and post-pubertal age groups.

The association of obesity with idiopathic intracranial hypertension is not as strong for pediatric $\operatorname{cases}^{15}$ as for those occurring within the adult population. ${ }^{16,17}$ The finding of $45 \%$ having a weight beyond the 95th percentile for age is higher than Babikian, ${ }^{15}$ but of similar magnitude. Despite opinion to the contrary, ${ }^{16}$ our data suggest that obesity is present both in preadolescents and adolescents. The observation that children with pseudotumor cerebri are taller than average is not unanticipated as children with this disease tend to be obese, and children who are obese tend to be taller than average and have an advanced bone age. ${ }^{17-19}$ This combination of increased weight and increased height probably accounts for comments that are made about the physiognomy of children with pseudotumor cerebri.

Lessell, ${ }^{16}$ in a recent review of pediatric pseudotumor cerebri, has discussed the issue of preference of the term pseudotumor cerebri over idiopathic intracranial hypertension on the basis that in the latter, patients with an apparent known etiology are excluded. Most "etiologic" agents for pediatric pseudotumor cerebri have only been described within case series and anecdotal 
reports, demonstrating association but not necessarily cause. Given the rarity of these "etiologic" agents, they have not been confirmed in a recent case-control study, ${ }^{20}$ presumably because of the necessary sample size. For this reason, we were not selective in attributing cause once Dandy's modified criteria were met. We did, however set a minimum age of two years, considering an earlier report from our centre ${ }^{21}$ which identified a number of young children with pseudotumor cerebri related to psychosocial/nutritional deprivation or cystic fibrosis. Recognizing these children as being different from our usual experience of pediatric pseudotumor cerebri, a minimum age was set.

Our numerator for our incidence estimates is relatively high ( $\mathrm{N}$ $=29$ ) and compares favorably with other population based studies done within North America (Radhakrishnan et al.: $\mathrm{N}=9{ }^{6}$ Durcan et al.: Iowa: $\mathrm{N}=27$; Louisiana: $\mathrm{N}=48 .^{7}$ )

We chose to study all cases presenting after April 1, 1979. This coincides with our medical records facility adoption of the ICD9 diagnostic codes. Previously pseudotumor cerebri was coded under several diagnostic codes, making case ascertainment less accurate. In addition, computerized tomography imaging was readily accessible during this period. As Canadian health care is provincially organized, only patients residing in provinces consistently served by our tertiary centre were included (Nova Scotia and Prince Edward Island). This also provided for reliable population estimates.

As with any study defining incidence rates, concern has to be raised as to whether all incident cases were identified. Several assumptions may be reviewed in order to accept our estimates: that pseudotumor cerebri presents with sufficient severity and duration in order to be brought to medical attention where it then is recognized or at least referred ultimately to a pediatric neurologist or pediatric opthalmologist. It is the clinical experience of pediatric neurologists that most patients with pseudotumor cerebri have significant symptomatology, however some authors discuss self limited illness, ${ }^{16}$ suggesting that if the identification or referral process is prolonged, that diagnosis may not be confirmed. Given our provincially organized health care system and distribution of pediatric sub-specialists, referral for complaints of this severity is prompt and usually to a subspecialist. In discussions with pediatricians within our region, all would refer cases of identified pseudotumor cerebri for pediatric neurological assessment. During this period, it was customary for cases of pseudotumor cerebri to be admitted for investigation and treatment. Finally no additional cases were identified through an audit of a diagnostic database, suggesting that our case identification was complete.

\section{CONCLUSION}

This study is unique in its provision of annual incidence rates for pediatric pseudotumor cerebri. It also documents an increasing incidence during adolescence and different sex specific incidence rates.

\section{REFERENCES}

1. Smith JL. Whence pseudotumor cerebri? J Clin Neuro-Opthalmol 1985; 5: 55-56.

2. Statistics Canada. The Nation: Age, Sex and Marital Status. Ottawa: Supply and Services Canada, 1987.

3. Fleiss JL. Statistical methods for rates and proportions. New York: John Wiley \& Sons, 1981.

4. Dean AG, Dean JA, Coulombier D, et al. Epi Info, Version 6: A word processing, database, and statistics program for epidemiology on microcomputers. Centers for Disease Control and Prevention, Atlanta, Georgia, USA, 1994.

5. Dibley MJ, Goldsby JB, Staehling NW, et al. Development of normalized curves for the international growth reference: historical and technical considerations. Am J Clin Nutr 1987; 46: 736-748.

6. Radhakrishnan K, Ahlskog JE, Cross SA. Idiopathic intracranial hypertension (pseudotumor cerebri). Arch Neurol 1993; 50: 78-80.

7. Durcan FJ, Corbett JJ, Wall M. The incidence of pseudotumor cerebri: population studies in Iowa and Louisiana. Arch Neurology 1988; 45: 875-877.

8. Rush JA. Pseudotumor cerebri (clinical profile and visual outcome in 63 patients). Mayo Clin Proc 1980; 55: 541-546.

9. Wall M, George D. Idiopathic intracranial hypertension. Brain 1991; 114: $155-180$

10. Boeri R. The pseudotumor cerebri. Curr Opinion Neurol 1994; 7 : 69-73.

11. Grant DN. Benign intracranial hypertension. Arch Dis Child 1971; 46: 651-655.

12. Rose A, Matson DD. Benign intracranial hypertension in children. Pediatrics 1967; 39: 227-237.

13. Weisberg JA, Chutorian AM. Pseudotumor cerebri of childhood. Am J Dis Child 1977; 131: 1243-1248.

14. Hagberg B, Sillanpaa M. Benign intracranial hypertension (pseudotumor cerebri). Acta Pediatr Scand 1970; 59: 328-339.

15. Babikian P, Corbett J, Bell W. Idiopathic intracranial hypertension in children: the Iowa experience 1994; 9: 144-149.

16. Lessel S. Pediatric pseudotumor cerebri (idiopathic intracranial hypertension). Surv Opthalmol 1992; 37: 155-166.

17. Forbes GB. Nutrition and growth. J Pediatr 1977; 91: 40-42.

18. Garn SM, Clark DC, Guire KE. Level of fatness and size attainment. Am J Phys Anthropol 1973; 40: 447-449.

19. Sargent JD, Blanchflower DG. Obesity and stature in adolescence and earnings in young adulthood: analysis of a British birth cohort. Arch Pediatr Adolesc Med 1994; 148: 681-687.

20. Ireland B, Corbett JJ, Wallace RB. The search for causes of idiopathic intracranial hypertension: a preliminary case-control study. Arch Neurol 1990; 47: 315-320.

21. Giuseffi V, Wall M, Seigel PZ, Rojas PB. Symptoms and disease associations in idiopathic intracranial hypertension (pseudotumor cerebri): a case-control study. Neurology 1991; 41: 239-244.

22. Couch $\mathrm{R}$, Camfield PR, Tibbles JAR. The changing picture of pseudotumor cerebri in children. Can J Neurol Sci 1985; 12: 48- 